\title{
СВЯЗЬ МЕЖДУ УРОВНЯМИ СМЕРТНОСТИ И ЭКОНОМИЧЕСКОГО РАЗВИТИЯ В РОССИИ
} И ЕЕ РЕГИОНАХ

\author{
ЕВГЕНИЙ АНДРЕЕВ, ВЛАДИМИР ШКОЛЬНИКОВ
}

\begin{abstract}
Богатые страны мира, как правило, отличает и более высокая продолжительность жизни. Мы проверили, верно ли это для регионов России.

Объектом исследования стали данные за 2010 г., год последней переписи населения. Мерой долголетия выступала ожидаемая продолжительность жизни при рождении, а мерой благосостояния - величина валового внутреннего продукта на душу населения в долларах США по паритету покупательной способности.
\end{abstract}
Анализ основан на сравнении данных России и ее регионов с кривой Престона, которая устанавливает связь между душевым ВВП и ожидаемой продолжительностью жизни при рождении. Кривая была рассчитана также для 2010 г по данным 57 стран, где демографическая статистика пригодна для расчета таблич смертности.

Мы установили, что ожидаемая продолжительность жизни в России существенно ниже уровня, который по модели Престона соответствует российскому душевому ВВП. В 2010 г. разница между модельной и реальной продолжительностью жизни составляла 8,7 лет и была самой высокой среди 57 стран, участвующих в расчете.

\begin{abstract}
Зависимость ожидаемой продолжительности жизни в регионе от экономического положения региона практически отсутствует. Иллюзия, что связь существует, есть следствие того, что Москва выделяется среди других регионов высоким ВВП и высокой продолжительностью жизни. Но и в Москве продолжительность жизни в 2010 г. была существенно ниже уровня, предсказанного моделью Престона. С нашей точки зрения, отсутствие связи объясняется тем, что в регионах с высоким ВВП также высок уровень экономического неравенства. Высокие доходы малой части населения могут поднять средний уровень экономических показателей, но более низкий уровень смертности в малой группе мало влияет на продолжительность жизни в регионе. Кроме того, высокий ВВП не означает автоматически более высокого уровня расходов на медицинскую помощь и обеспечение безопасности жизни.
\end{abstract}

Ключевые слова: продолжительность жизни, валовой внутренний продукт, кривая Престона, регионы России, экономическое неравенство, неравенство в смертности.

\section{1. ВВЕДЕНИЕ}

Принято считать, что более богатые страны мира отличает и более высокая продолжительность жизни. Так, по оценкам Отдела населения ООН, разрыв в ожидаемой продолжительности жизни при рождении между группами стран с высоким и средним доходом с одной стороны, и со средним и низким доходом, с другой, в настоящее время составляет около 10 лет [WPP 2017].

ЕВГЕНИЙ МИХАЙЛОВИч АНДРЕЕВ (evand2009@yandex.ru), НАЦИОНАЛЬНЫЙ ИССЛЕДОВАТЕЛЬСКИЙ УНИВЕРСИТЕТ «ВЫСШАЯ ШКОЛА ЭКОНОМИКИ», РОССИЯ.

ВЛАДИМИР МИХАЙЛОВИч ШКОЛЬНИКОВ (shkolnikov@demogr.mpg.de), ИНСТИТУТ ДЕМОГРАФИЧЕСКИХ ИССЛЕДОВАНИЙ ОБЩЕСТВА МАКСА ПЛАНКА, ГЕРМАНИЯ.

СТАТЬЯ ПОСТУПИЛА В РЕДАКЦИЮ В ДЕКАБРЕ 2017 Г. 
Насколько нам известно, первую попытку описать эту связь предпринял в 1975 г. Сэмюель Престон [Preston 1975]. Кривая Престона описывает связь между продолжительностью жизни в определенный календарный период и валовым внутренним продуктом страны, показателем, характеризующим текущий подушевой доход и, в значительной степени, уровень экономического развития. Престон изучал зависимость продолжительности жизни от ВВП для 1900-х, 1930-х и 1960-х гг. и обнаружил, что форма связи между переменными одна и та же в каждое десятилетие. При этом со временем кривая Престона сдвигается в вертикальном и (менее интенсивно) в горизонтальном направлении по мере роста продолжительности жизни и душевого ВВП, соответственно. Кривая Престона широко используется в работах по экономике и политологии. В качестве примера мы сошлемся на известную, посвященную России работу Н. Эберштата [Eberstadt 2010].

Естественный вопрос - в какой мере описанная Престоном закономерность справедлива для России на субнациональном уровне и справедлива вообще. Интерес к региональной теме усиливается благодаря тому, что Москва - самый большой по численности населения субъект Российской Федерации, в настоящее время характеризуется самой высокой в России ожидаемой продолжительностью жизни и занимает третье место по величине валового регионального продукта на душу населения.

Современный вариант кривой Престона использует в качестве меры дохода величину ВВП на душу населения в долларах США по паритету покупательной способности. Этот же показатель используется для расчета индекса человеческого развития и вместе с ожидаемой продолжительностью жизни при рождении регулярно публиковался в издававшихся ПРООН докладах о человеческом развитии в Российской Федерации.

Первые такие данные относятся к 1999 г. и были опубликованы в докладе 2001 г. [ПРООН 2002: 82-93] При знакомстве с таблицей «Индекс развития человеческого потенциала по регионам РФ за 1999 год» обращает на себя внимание практическое отсутствие связи между душевым ВВП и ожидаемой продолжительностью жизни. 1999 г. не исключение, подобный вывод можно сделать из каждого доклада о человеческом развитии.

Этот факт и определил тему данной публикации. Наша главная цель - оценить степень влияния уровня экономического развития на уровень продолжительности жизни. Особое внимание будет уделено ситуации в стране в целом и в Москве. В анализе используются в основном данные за 2010 г. - год последней всеобщей переписи населения.

\section{2. МЕТОДОЛОГИЯ ИССЛЕДОВАНИЯ}

Наш анализ опирается на разработанную Престоном формулу, описывающую связь национального дохода на душу населения и ожидаемой продолжительности жизни при рождении для обоих полов вместе, известную как кривая Престона.

$$
e_{0}=\frac{80}{1+\exp \left(a+b \cdot \mathrm{e}^{c \cdot Y}\right)} .
$$


Согласно Престону, $Y$ представляет собой линейную функцию от национального дохода на душу населения в долларах США. Константа 80 - верхний предел ожидаемой продолжительности жизни при рождении для обоих полов вместе в 1970-ые гг. Кроме того, формула включает в себя три параметра, $a, b, c$, которым автор приписывает некоторое экономическое толкование. Если бы не это толкование, т.е. если мы предположим, что $a, b, c$ - формальные параметры, то дополнительное преобразование не потребуется. В современной редакции модели используется не национальный доход, а валовой внутренний продукт, который обычно измеряется в национальной валюте. При переходе к одной единице измерения естественно учитывать не курсы валют, а покупательную способность. Таким образом, в качестве независимого параметра модели целесообразно взять ВВП на душу населения в долларах США по паритету покупательной способности или кратко «душевой ВВП».

В начале 2000-х гг. продолжительность жизни 80 лет уже была достигнута в ряде стран, и в качестве верхнего предела ожидаемой продолжительности жизни при рождении можно взять, например, 100 лет. Однако оказалось, что практически та же зависимость может быть описана существенно более простой двухпараметрической формулой [Preston 2007; Edwards 2016]

$$
e_{0}=A+B \cdot \ln (Y)
$$

где $e_{0}$ - ожидаемая продолжительность жизни для обоих полов вместе, а $Y$ - душевой ВВП.

В той области, где реально меняются $Y$ и $e_{0}$, результаты расчетов по двум разным формулам отличаются не более чем на 0,1 года. Именно второй вариант модели Престон представил в работе 2007 г. [Preston 2007].

Для решения поставленной во введении задачи мы применили следующий прием. На основе данных по избранной совокупности стран мы определили параметры кривой Престона, а затем проанализировали расположение относительно этой кривой точек, соответствующих России и ее регионам.

При анализе результатов моделирования был использован метод декомпозиции для анализа различий в продолжительности жизни между странами и регионами с близким душевым ВВП по возрастам и причинам смерти [Andreev, Shkolnikov, Begun 2002],

\section{3. ДАННЫЕ}

\section{1. ВВП и продолжительность жизни в России и ее регионах}

Наш анализа опирается на данные за 2010 г. - год последней Всероссийской переписи населения. Общеизвестно, что демографические показатели, рассчитанные с использованием материалов переписи, точнее, чем в годы после переписи. Показатели за последующие годы могут быть неточны в силу ошибок переписи, если таковые были, и ошибок, возникших при расчете состава населения на последующие годы в результате неточности учета движения населения. Судя по опыту прошлых лет, это, главным образом, 
ошибки учета миграции. Отметим, что точность переписи населения Москвы тоже подвергалась критике [Андреев 2012]. Хотя сомнения в точности переписи сохраняются, в этой статье мы полагаем, что результаты переписи 2010 г. в Москве достаточно точны. Отметим, что, начиная с 2011 г., после изменения границ Москвы, показатель продолжительности жизни в возрасте 80 лет начинает расти так быстро и достигает таких исключительно высоких значений, что возникают сомнения в надежности данных. И в этом еще одна из причин ограничиться 2010 годом [Папанова и др. 2018].

Ожидаемая продолжительность жизни в регионах Российской Федерации публиковалась несколько раз, как до, так и после завершения обработки результатов переписи населения 2010 г. Чтобы избежать путаницы, мы снова рассчитали ожидаемую продолжительность жизни в регионах, опираясь на Российскую базу данных по рождаемости и смертности [РосБРиС 2017]. Наши результаты совпали с последними расчетами, опубликованными Росстатом. Мы также использовали возрастные коэффициенты смертности по причинам смерти по России и регионам из той же базы данных. В расчете участвовали субъекты федерации, не входившие в состав другого субъекта федерации.

Росстат не рассчитывает душевой ВВП по регионам России, но в докладах о человеческом развитии в Российской Федерации более десятилетия публикуются оценки этого показателя, который использовался для расчета индекса человеческого развития по российским регионам. Показатель за 2010 г. опубликован в докладе 2013 г. [ПРООН 2013: $150-151]$

Методика расчета ВВП по регионам разработана Н. В. Зубаревич [2003]. Расчет основан на публикуемых Росстатом данных о валовом региональном продукте (ВРП) и стоимости фиксированной корзины потребительских товаров и услуг в регионе. Последняя публикация данных за 2010 г. была выпущена в 2014 г. [Росстат 2014: 347-349, 865-866]. Мы сочли целесообразным повторить расчет, поскольку, возможно, показатели валового регионального продукта и стоимости фиксированного набора потребительских товаров и услуг были уточнены по сравнению с использованными в расчетах для доклада о человеческом развитии. Кроме того душевой ВВП для России в целом в Докладе о человеческом развитии был несколько ниже оценки Всемирного банка для России (19674 по сравнению с 20770). Поскольку для других участвующих в расчетах стран мы использовали именно оценку Всемирного банка, мы сочли целесообразным использовать ее и для России.

Серьезные сомнения вызывают данные по шести республикам Северо-Кавказского ФО из-за неуверенности в точности данных о численности населения, полученных в переписи 2010 г. [Андреев 2012]. В целом, эти республики отличает сочетание чрезвычайно низкого душевого ВВП и высокой ожидаемой продолжительности жизни.

\section{2. ВВП и продолюсительность жсизни в других странах}

В данном исследовании мы решили ограничиться странами, для которых таблицы смертности за 2010 г. были рассчитаны традиционным методом, т.е. на основе повозрастных чисел умерших и численности населения под риском как для мужчин и 
женщин раздельно, так и для обоих полов вместе. Мы исключили из рассмотрения страны, для которых оценки ожидаемой продолжительности жизни были получены косвенными методами. Наш список включает 40 стран Европейского регионального бюро BO3 [EHA DB 2017] и 16 стран Регионального отделения ВОЗ для стран Америки [РАНО 2014]. Помимо этих двух групп, мы обнаружили три страны, где показатели смертности в 2010 г. были рассчитаны традиционными методами: Япония, Австралия и Новая Зеландия. Для стран, включенных в базу данных смертности человека (HMD), мы отдавали предпочтение данным из этой базы [HMD 2017].

Для России мы использовали результат наших собственных расчетов, полностью сопоставимых с расчетами по регионам.

Кроме того, была использована информация из базы данных ВО3 [WHO Mortality Database 2017] о распределении умерших по причинам смерти для некоторых стран.

Душевой ВВП для всех стран, включая Россию, за 2010 г. был взят из базы данных Всемирного банка [World Development Indicators 2017].

Решение ограничить список стран, участвующих в анализе, нуждается в некотором объяснении. Отдел населения ООН выполняет оценки ожидаемой продолжительности жизни для всех стран мира. Многие авторы используют эти данные для анализа тенденций и факторов динамики смертности. Нам кажется, что такой анализ преувеличивает надежность модельных оценок смертности и продолжительности жизни в развивающихся странах, в которых статистика смертности либо полностью отсутствует, либо недостоверна. На рисунке 1 представлены два варианта кривой Престона за 2010 г., которые принципиально отличаются друг от друга.

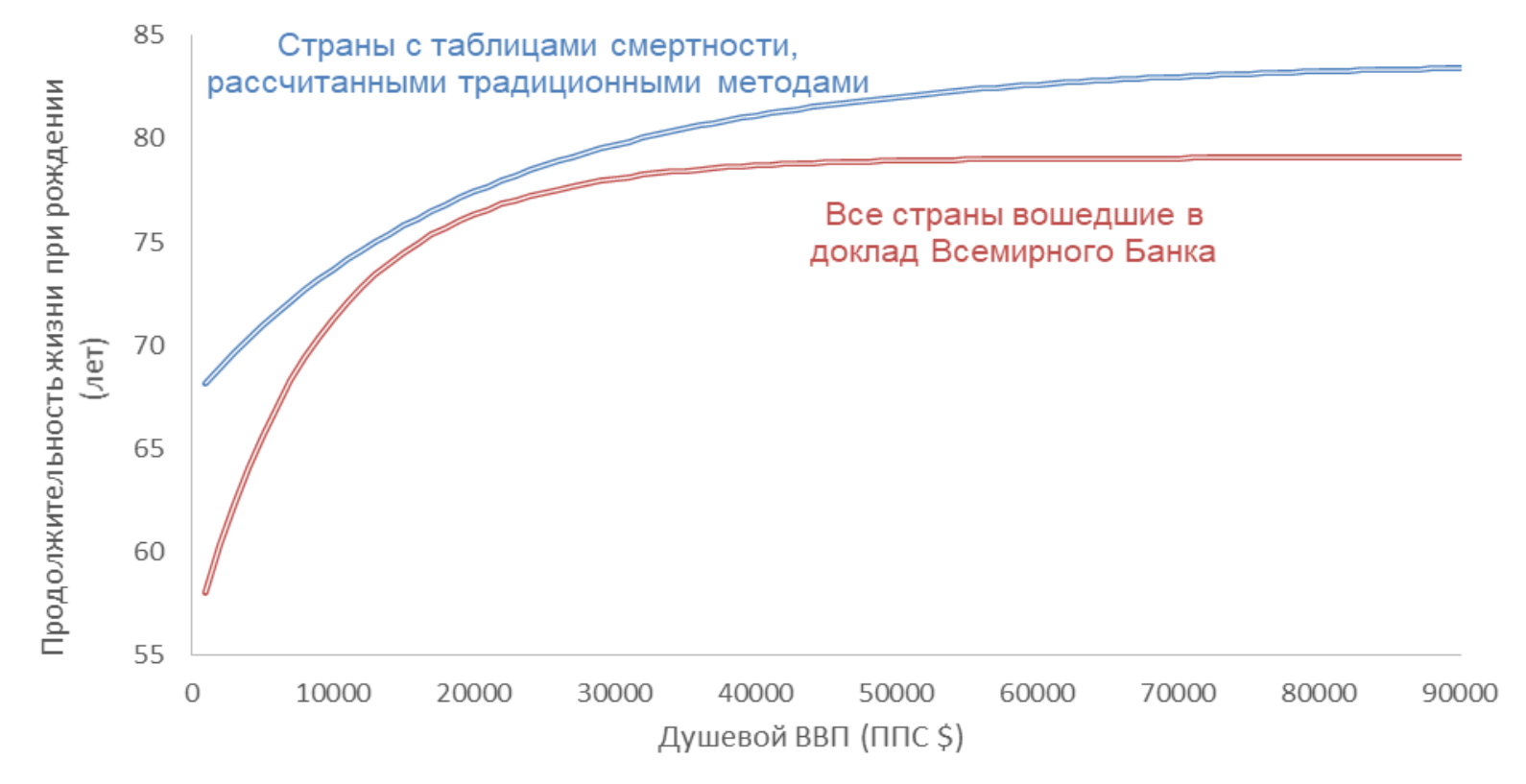

\section{Рисунок 1. Кривые Престона для стран с таблицами смертности, рассчитанными традиционными методами, и для всех стран из отчета Всемирного банка}

Источник: расчет авторов на основе данных, описанных в разделе 3. 
Для кривой, основанной данных для всех стран ожидаемая продолжительность жизни почти не растет в области высоких значений ВВП на душу населения. На основе таких данных, например, был сделан вывод, что в настоящее время кривая Престона утратила свое значение [Georgiadis et al. 2010]. На наш взгляд, дело в том, что косвенные оценки продолжительности жизни в целом преуменьшают различия между странами, в результате чего кривая Престона приближается к горизонтальной линии, почти не зависящей от ВВП.

\section{4. РеЗУЛЬТАТЫ}

На рисунке 2 представлено распределение стран по душевому ВВП и ожидаемой продолжительности жизни при рождении. На плоскость нанесены точки для 57 стран, для которых было возможно рассчитать таблицу смертности за 2010 г. традиционным методом. На основе этих данных были оценены параметры представленной на графике кривой Престона. Для определения параметров модели мы использовали процедуру линейной регрессии из SPSS. Параметры кривой Престона оказались равными $A=31,75$ и $B=4,61$, при этом $R^{2}=0,68, F$ тест уровня статистической значимости равен 119,0 при р <0,0001.

Мы нанесли на ту же диаграмму рассеивания данные для регионов России. При этом точки для Республики Тыва и Чукотского автономного округа отсутствуют на рисунке изза того, что ожидаемая продолжительность жизни в этих двух регионах (соответственно 60,5 и 57,4 года) была значительно ниже, чем в других регионах и странах. Если бы мы их поместили на график, то он стал бы слишком мелким.

Точки, соответствующие 28 странам из нашего списка, лежат на диаграмме рассеивания выше кривой Престона, а 29 - под кривой. Среднее отклонение стран от кривой составляет -0,08. Это означает, что распределение стран почти симметрично относительно кривой Престона. Конечно, точки существенно рассеяны вокруг кривой. Среднеквадратичное отклонение составляет 2,34 года. Коэффициенты ранговой корреляции Кендалла и Спирмена между душевым ВВП и ожидаемой продолжительностью жизни значимы на уровне 0,01 (здесь и далее приводится двусторонняя оценка) и равны соответственно 0,63 и 0,84 .

Точки, соответствующие России и ее регионам, кроме Ингушской и Чеченской республик, лежат под кривой Престона. По ВВП на душу населения в 2010 г. Россия была близка к странам успешного перехода к рыночной экономике - таким, как Эстония и Польша. Однако, по уровню продолжительности жизни разница между оценкой продолжительности жизни по модели Престона и ожидаемой продолжительностью жизни в регионах находится в интервале от -5,2 года (Ингушская республика) до 23,3 лет (Чукотский автономный округ). Для Москвы это различие составляет 7,2 года. Среднее различие между фактической и ожидаемой продолжительностью жизни и ее модельными значениями для регионов России равно 8,0 годам. Если исключить шесть республик Северо-Кавказского ФО, то среднее различие между фактической ожидаемой продолжительностью жизни и ее модельными значениями составит 8,4 года. 
Дальнейший статистический анализ мы провели без шести республик СевероКавказского ФО, которые резко выделяются среди всех регионов. Сочетание очень низкого ВВП и относительно высокой продолжительности жизни в шести регионах препятствует использованию ранговой корреляции: кажется, что продолжительность жизни снижается с ростом ВВП.

Важно отметить, что отклонение российских регионов от кривой Престона нарастает с увеличением душевого ВВП. Коэффициенты ранговой корреляции Кендалла и Спирмена между величиной душевого ВВП и разницей между оценкой продолжительности жизни по модели Престона и фактическими значениями продолжительности жизни в регионах значимы на уровне 0,01. Эти коэффициенты составляют соответственно 0,49 и 0,65. Мы попробовали исключить регионы с самым высоким душевым ВВП (Тюменская и Сахалинская области, Москва, Чукотский автономный округ), однако коэффициенты ранговой корреляции практически не изменились.

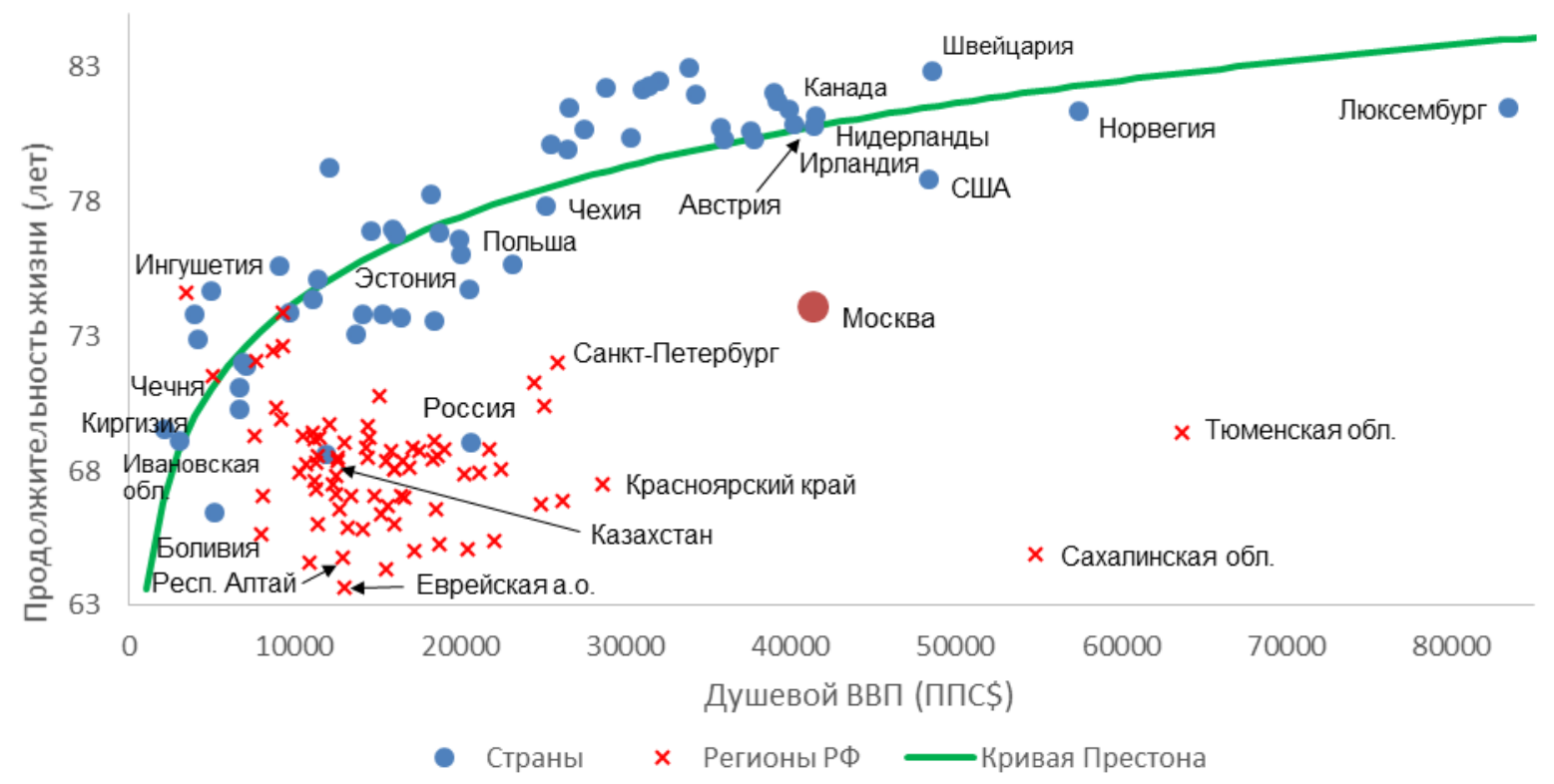

\section{Рисунок 2. Распределение 57 стран и 80 регионов России по душевому ВВП и ожидаемой продолжительности жизни при рождении в 2010 г.}

Источник: расчет авторов на основе данных, описанных в разделе 3.

Попытка сравнить уровень экономического развития и ожидаемую продолжительность жизни только в регионах России не увенчалась успехом. Поиск параметров кривой Престона на основе региональных данных дает горизонтальную линию, параллельную оси душевого ВВП. Коэффициенты ранговой корреляции Кендалла и Спирмена между душевым ВВП и ожидаемой продолжительностью жизни парадоксальны: они имеют небольшие отрицательные значения $(-0,14$ и $-0,20)$ и статистически значимы на пограничном уровне значимости $\mathrm{p}=0,08$.

В четырех странах: Австрия, Канада, Ирландия и Нидерланды, в 2010 г. душевой ВВП был примерно таким же, как в Москве. Точки, соответствующие этим странам, лежат почти на кривой Престона. Отличие продолжительности жизни для обоих полов по модели 
(ожидаемое значение на основе ВВП) и от рассчитанной по данным статистики в Москве составляет 6,7 года. Отличие московского показателя от средней для четырех стран несколько больше - 7,2 года.

Разница в продолжительности жизни при рождении между указанными четырьмя странами и Москвой для мужчин составляла 8,9 года, и $72 \%$ от этой величины связаны с возрастами от 15 до 64 лет (Таблица 1). При этом 67\% различий обусловлены болезнями системы кровообращения (БСК), в т.ч. $38 \%$ связаны с ишемической болезнью сердца и $21 \%$ - с цереброваскулярными расстройствами. Вклад этих групп причин распределяется между возрастными группами 15-64 года и 65 лет и старше приблизительно как один к двум. Вклад почти всех других причин сосредоточен в возрасте от 15 до 64 лет. Второе место после БСК занимали внешние причины, однако их вклад в семь раз меньше, чем вклад БСК.

Таблица 1. Декомпозиция различий в ожидаемой продолжительности жизни между Австрией, Канадой, Ирландией и Нидерландами (суммарно), и Москвой в 2010 г. по возрасту и отдельным причинам смерти для мужчин и женщин (лет)

\begin{tabular}{|c|c|c|c|c|c|c|c|c|}
\hline \multirow[b]{2}{*}{$\begin{array}{l}\text { Причины смерти и соответствующие } \\
\text { коды МКБ-10 }\end{array}$} & \multicolumn{4}{|c|}{ Мужчины } & \multicolumn{4}{|c|}{ Женщины } \\
\hline & 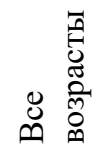 & $\frac{1}{0}$ & $\begin{array}{l}\text { to } \\
\stackrel{1}{1}\end{array}$ & $\stackrel{+}{6}$ & 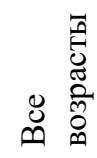 & $\frac{ \pm}{0}$ & $\begin{array}{l}\text { ț } \\
\stackrel{1}{2}\end{array}$ & $\stackrel{+}{6}$ \\
\hline Все причины, A00-R99, V01-Y98 & 8,89 & 0,43 & 6,38 & 2,07 & 5,33 & 0,37 & 2,00 & 2,95 \\
\hline $\begin{array}{l}\text { Болезни системы кровообращения, I00- } \\
\text { I99 }\end{array}$ & 5,96 & $-0,01$ & 2,93 & 3,05 & 5,33 & $-0,01$ & 0,94 & 4,39 \\
\hline Ишемическая болезнь сердца, I20-I25 & 3,37 & 0,00 & 1,30 & 2,08 & 3,28 & 0,00 & 0,35 & 2,92 \\
\hline $\begin{array}{l}\text { Цереброваскулярные расстройства, I60- } \\
\text { І69 }\end{array}$ & 1,90 & 0,00 & 0,59 & 1,31 & 2,21 & 0,00 & 0,26 & 1,95 \\
\hline $\begin{array}{l}\text { Другие болезни системы } \\
\text { кровообращения, остальные из I00-I99 }\end{array}$ & 0,69 & $-0,01$ & 1,04 & $-0,34$ & $-0,16$ & $-0,01$ & 0,33 & $-0,48$ \\
\hline Новообразования, C00-D48 & 0,23 & 0,06 & 0,32 & $-0,15$ & 0,05 & 0,05 & 0,13 & $-0,13$ \\
\hline Инфекционные болезни, А00-В99 & 0,41 & 0,02 & 0,43 & $-0,04$ & 0,11 & 0,02 & 0,16 & $-0,07$ \\
\hline $\begin{array}{l}\text { Перинатальные причины и врожденные } \\
\text { аномалии, P00-P96, Q00-Q99 }\end{array}$ & 0,30 & 0,31 & $-0,01$ & 0,00 & 0,25 & 0,25 & 0,00 & 0,00 \\
\hline $\begin{array}{l}\text { Другие болезни и состояния, остальные } \\
\text { коды из А00-R99 }\end{array}$ & 1,09 & 0,02 & 1,89 & $-0,81$ & $-0,59$ & 0,01 & 0,62 & $-1,23$ \\
\hline Внешние причины, Ү01-Ү98 & 0,90 & 0,04 & 0,83 & 0,02 & 0,19 & 0,05 & 0,15 & $-0,01$ \\
\hline
\end{tabular}

Источник: расчет авторов на основе данных, описанных в разделе 3.

Разница между четырьмя странами и Москвой для женщин составляет 5,3 года которые целиком обусловлены различиями в смертности от БСК. Свыше 80\% вклада БСК приходится на возрасты 65 лет и старше.

Россию уместно сравнить с Польшей, которая одновременно очень близка к кривой Престона и очень близка к России по уровню душевого ВВП. Разница в ожидаемой продолжительности жизни между Польшей и Россией в 2010 г. для обоих полов вместе составила 7,7 года, в то время как отклонение России от кривой Престона на 1 год больше и составляет 8,6 года. Отличие Польши от России для мужчин составило 8,9 года, для женщин - 5,5 года.

В таблице 2 представлена декомпозиция различий в ожидаемой продолжительности жизни между Польшей и Россией по возрасту и причинам смерти для мужчин и женщин. 
Мы предлагаем сравнить результаты этой декомпозиции с декомпозицией различий между Польшей и Москвой.

Таблица 2. Декомпозиция различий в ожидаемой продолжительности жизни между Польшей и Россией в 2010 г. по возрасту и отдельным причинам смерти для мужчин и женщин (лет)

\begin{tabular}{|c|c|c|c|c|c|c|c|c|}
\hline \multirow[b]{2}{*}{$\begin{array}{l}\text { Причины смерти и соответствующие } \\
\text { коды МКБ- } 10\end{array}$} & \multicolumn{4}{|c|}{ Мужчины } & \multicolumn{4}{|c|}{ Женщины } \\
\hline & 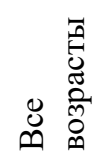 & $\frac{1}{0}$ & $\begin{array}{l}\text { ț } \\
\stackrel{1}{2}\end{array}$ & $\stackrel{+}{6}$ & 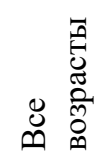 & $\frac{ \pm}{0}$ & $\begin{array}{l}\text { ț } \\
\stackrel{1}{2}\end{array}$ & $\stackrel{+}{6}$ \\
\hline Все причины, A00-R99, V01-Y98 & 8,93 & 0,45 & 6,71 & 1,77 & 5,51 & 0,37 & 2,87 & 2,26 \\
\hline $\begin{array}{l}\text { Болезни системы кровообращения, I00- } \\
\text { I99 }\end{array}$ & 4,34 & 0,01 & 2,48 & 1,85 & 3,83 & 0,01 & 1,20 & 2,62 \\
\hline $\begin{array}{l}\text { Ишемическая болезнь сердца, } \\
\text { I20-I25 }\end{array}$ & 3,03 & 0,00 & 1,51 & 1,52 & 2,77 & 0,00 & 0,60 & 2,18 \\
\hline $\begin{array}{l}\text { Цереброваскулярные } \\
\text { расстройства, I60-I69 }\end{array}$ & 1,34 & 0,00 & 0,50 & 0,84 & 1,77 & 0,00 & 0,33 & 1,44 \\
\hline $\begin{array}{l}\text { Другие болезни системы } \\
\text { кровообращения, остальные из } \\
\text { I00-I99 }\end{array}$ & $-0,03$ & 0,01 & 0,47 & $-0,51$ & $-0,71$ & 0,01 & 0,27 & $-0,99$ \\
\hline Новообразования, C00-D48 & $-0,02$ & 0,01 & 0,15 & $-0,19$ & $-0,25$ & 0,01 & 0,00 & $-0,27$ \\
\hline Инфекционные болезни, А00-В99 & 0,55 & 0,02 & 0,53 & 0,00 & 0,21 & 0,02 & 0,21 & $-0,02$ \\
\hline $\begin{array}{l}\text { Перинатальные причины и врожденные } \\
\text { аномалии, P00-P96, Q00-Q99 }\end{array}$ & 0,13 & 0,12 & 0,01 & 0,00 & 0,10 & 0,09 & 0,01 & 0,00 \\
\hline $\begin{array}{l}\text { Другие болезни и состояния, остальные } \\
\text { коды из A00-R99 }\end{array}$ & 0,71 & 0,08 & 0,62 & 0,00 & 0,58 & 0,07 & 0,52 & $-0,02$ \\
\hline Внешние причины, Y01-Y98 & 2,78 & 0,17 & 2,50 & 0,10 & 1,00 & 0,13 & 0,83 & 0,05 \\
\hline
\end{tabular}

Источник: расчет авторов на основе данных, описанных в разделе 3.

Различия между Польшей и Россией по продолжительности жизни близки по величине к различиям между Москвой и суммой четырех западных стран, как для мужчин, так и для женщин. Различие у мужчин определялось избыточной смертностью в рабочих возрастах 15-64 лет и (в равной мере) смертностью от БСК и внешних причин. У женщин разрыв в продолжительности жизни был почти в равной степени обусловлен избыточной смертностью в возрастах 15-64 и 65 лет и старше. В рабочих возрастах он определялся БСК, внешними причинами и «другими болезнями и состояниями», а возрастах 65 лет и старше - БСК.

Наконец, в таблице 3 представлен вклад отдельных причин и возрастных групп в намного меньшие различия между ожидаемой продолжительностью жизни в Польше и в Москве, которые составляют 2,7-2,6 года у мужчин и женщин. Наибольший вклад и у мужчин, и у женщин вносят БСК. Для женщин вклады всех других причин кажутся несущественными. Для мужчин более низкая смертность от новообразований в Москве заметно уменьшает разницу в продолжительности жизни между Польшей и Москвой. В той же мере группа «Другие болезни и состояния» эту разность увеличивает. 
Таблица 3. Декомпозиция различий в ожидаемой продолжительности жизни между Польшей и Москвой в 2010 г. по возрасту и отдельным причинам смерти для мужчин и женщин (лет)

\begin{tabular}{|c|c|c|c|c|c|c|c|c|}
\hline \multirow[b]{2}{*}{$\begin{array}{l}\text { Причины смерти и } \\
\text { соответствующие коды МКБ-10 }\end{array}$} & \multicolumn{4}{|c|}{ Мужчины } & \multicolumn{4}{|c|}{ Женщины } \\
\hline & 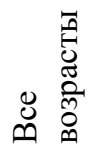 & $\frac{1}{0}$ & 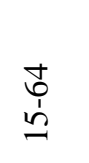 & $\stackrel{+}{6}$ & 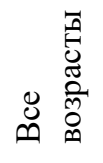 & $\frac{ \pm}{0}$ & 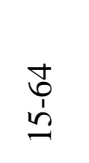 & 怘 \\
\hline Все причины, A00-R99, V01-Y98 & 2,82 & 0,34 & 2,43 & 0,05 & 2,69 & 0,30 & 1,19 & 1,20 \\
\hline $\begin{array}{l}\text { Болезни системы } \\
\text { кровообращения, I00-I99 }\end{array}$ & 2,16 & $-0,01$ & 1,45 & 0,72 & 2,22 & $-0,02$ & 0,54 & 1,69 \\
\hline $\begin{array}{l}\text { Ишемическая болезнь } \\
\text { сердца, I20-I25 }\end{array}$ & 2,21 & 0,00 & 0,87 & 1,35 & 2,46 & 0,00 & 0,29 & 2,18 \\
\hline $\begin{array}{l}\text { Цереброваскулярные } \\
\text { расстройства, I60-I69 }\end{array}$ & 0,91 & 0,00 & 0,29 & 0,63 & 1,32 & 0,00 & 0,14 & 1,18 \\
\hline $\begin{array}{l}\text { Другие болезни системы } \\
\text { кровообращения, } \\
\text { остальные из I00-I99 }\end{array}$ & $-0,97$ & $-0,01$ & 0,29 & $-1,25$ & $-1,56$ & $-0,01$ & 0,12 & $-1,66$ \\
\hline Новообразог & $-0,71$ & 0,05 & $-0,30$ & $-0,46$ & $-0,17$ & 0,04 & $-0,14$ & $-0,07$ \\
\hline Инфекцион & 0,36 & 0,01 & 0,37 & $-0,01$ & 0,15 & 0,01 & 0,15 & $-0,02$ \\
\hline $\begin{array}{l}\text { Перинатальные причины и } \\
\text { врожденные аномалии, Р00-P96, } \\
\text { Q00-Q99 }\end{array}$ & 0,24 & 0,23 & 0,01 & 0,00 & 0,18 & 0,17 & 0,01 & 0,00 \\
\hline $\begin{array}{l}\text { Другие болезни и состояния, } \\
\text { остальные коды из A00-R99 }\end{array}$ & 0,80 & 0,04 & 0,93 & $-0,17$ & 0,13 & 0,05 & 0,49 & $-0,40$ \\
\hline Внешние причины, Y01-Y98 & $-0,03$ & 0,02 & $-0,02$ & $-0,03$ & 0,18 & 0,04 & 0,14 & 0,00 \\
\hline
\end{tabular}

Источник: расчет авторов на основе данных, описанных в разделе 3.

\section{5. ОБСУЖДЕНИЕ И ВЫВОДЫ}

На основе данных для стран, где качество статистики населения позволяет рассчитать надежные таблицы смертности, мы установили, что форма кривой Престона в 2010 г. существенно не изменились по сравнению с данными за более ранние периоды, показанные в пионерной статье Престона 1975 г.

В то же время для регионов России душевой ВВП кажется не связанным с ожидаемой продолжительностью жизни. Как следствие, отклонение продолжительности жизни в регионах от кривой Престона увеличивается с увеличением душевого ВВП. Единственное исключение - Москва, в которой высокий ВВП на душу населения сочетается с высокой (по сравнению с другими регионами) продолжительностью жизни. В ряде случаев относительно низкая ожидаемая продолжительность жизни в регионах с относительно высоким душевым ВВП может быть объяснена тяжелыми природноклиматическими условиями. Но это объяснение не позволяет понять всю картину. Например, того факта, что положительная корреляция между душевым ВВП и ожидаемой продолжительностью жизни отсутствует даже в европейской части страны. Коэффициенты ранговой корреляции Кендалла и Спирмена между душевым ВВП и ожидаемой продолжительностью жизни незначимы и почти равны нулю. 
Мы попытались понять, какие причины смерти определяют отклонение России и ее регионов от кривой Престона, сравнив смертность по причинам в России в целом и в Москве с аналогичными данными для близких по уровню ВВП стран.

Нам не удалось узнать ничего принципиально нового. Основные отличия (отклонения от кривой Престона) связаны с БСК, а также, в случае России в целом - с внешними причинами. Взамен в Москве у мужчин в средних возрастах неожиданно дает существенный вклад группа «Другие болезни и состояния». Возможное объяснение этого явления предложено В.Г. Семеновой и О.И. Антоновой [2007], которые утверждали, что в Москве часть смертей от внешних причин ошибочно классифицируется как смерть от неустановленных причин. С учетом этого мы можем заключить, что вклад группы «Другие болезни и состояния» у женщин точнее, чем у мужчин, отражает реальные черты смертности в Москве. Отметим, что после 2010 г. подобная практика распространилась и на многие другие регионы.

Сравнение смертности по причинам в Москве и Польше также указывает на БСК, как главную причину различий в продолжительности жизни. У мужчин разница концентрируется в возрастах от 15 до 64 лет, возможно, это можно связать с более высоким, чем в Польше, уровнем потребления алкоголя не только во всей России, но и в Москве.

Получается, что причины смерти, определяющие отклонение от кривой Престона, мало меняются с изменением ВВП.

В то же время, экономические характеристики качества жизни, например, средний доход на душу населения в регионе выше в тех регионах, где уровень ВВП выше [Зубаревич 2003]. Мы сопоставили региональные данные о душевом ВВП с данными о среднем доходе на душу населения в 2010 г. [Росстат 2014: 162-163] Оказалось, что коэффициенты ранговой корреляции Кендалла и Спирмена между душевым ВВП и средним доходом на душу населения соответственно равны 0,61 и 0,81. Корректировка доходов по покупательной способности не меняет корреляции. А вот ранговая корреляция между ожидаемой продолжительностью жизни и средним доходом в 2010 г., как фактическим, так и скорректированным с учетом покупательной способности, незначима, и соответствующие коэффициенты почти равны нулю.

В регионах, где выше уровень среднедушевого дохода, существенно выше и неравенство населения по уровню дохода. Мы воспользовались данными о распределении населения по денежным доходам в регионах России в 2010 г. (оценка на основе материалов выборочного обследования бюджетов домашних хозяйств) и рассчитанным на их основе коэффициентом Джини [Росстат 2011: 162-163] Оказалось, что коэффициенты ранговой корреляции Кендалла и Спирмена между душевым ВВП и коэффициентом Джини распределения регионального населения по денежным доходам в 2010 г. составляют, соответственно, 0,41 и 0,58, и значимы на уровне 0,01 .

Мы провели дополнительное тестирование и напрямую сравнили ожидаемую продолжительность жизни в регионах с высоким и низким доходом или высоким и низким коэффициентом Джини. Для этого была найдена средняя ожидаемая продолжительность жизни для 10 регионов с самым высоким и самым низким доходом и с самым высоким и 
самым низким коэффициентом Джини. В 10 регионах с самым низким доходом средняя для группы ожидаемая продолжительность жизни составляет 67,4 года, а с самым высоким доходом - 67,3 года. В 10 регионах с самым высоким коэффициентом Джини средняя для группы ожидаемая продолжительность жизни также составляет 67,3 года, а в группе с самым низким коэффициентом - 68,7 года. Получается, что низкий уровень экономического неравенства оказывает более сильное влияние на продолжительность жизни, чем сам по себе средний уровень доходов.

Связи между региональными расходами на здравоохранение, душевым ВВП и ожидаемой продолжительностью жизни в регионах также выглядят неясными. Нам удалось обнаружить по регионам только данные о финансировании по программе государственных гарантий предоставления бесплатной медицинской помощи гражданам России (ПГГ) [Росстат 2011: 286-289]. В 2010 г. этот показатель содержит стоимость средств обязательного медицинского страхования, а также расходы федерального и регионального бюджетов. Мы не сочли возможным корректировать данные о финансировании ПГГ с учетом покупательной способности, поскольку неясно, в какой мере стоимость фиксированного набора потребительских товаров и услуг может служить основой для расчетов. К тому же медицинская помощь жителям региона по ПГГ из ее средств может осуществляться в лечебных учреждениях других регионов.

Расходы, как и ожидалось, увеличиваются с ростом регионального душевого ВВП (таблица 4). Однако весьма неожиданно выглядит вторая половина таблицы 4, указывающая на отрицательную корреляцию между продолжительностью жизни и расходами на здравоохранение. Причем отрицательная связь наблюдается и в Европейской части страны, где тяжелые природно-климатические не играют той роли, как к востоку от Урала.

Таблица 4. Коэффициенты корреляции между финансированием региональной программы государственных гарантий предоставления бесплатной медицинской помощи на душу населения и душевым ВВП и ожидаемой продолжительностью жизни при рождении в 2010 г.

\begin{tabular}{|c|c|c|c|c|}
\hline & \multicolumn{2}{|c|}{ Россия в целом } & \multicolumn{2}{|c|}{ Европейская часть* } \\
\hline & Кендалла & Спирмена & Кендалла & Спирмена \\
\hline & \multicolumn{4}{|c|}{ ранговые коэффициенты корреляции между } \\
\hline & \multicolumn{4}{|c|}{ Душевой ВВП } \\
\hline $\begin{array}{l}\text { Объемом финансирования региональной ПГГ } \\
\text { на душу населения }\end{array}$ & 0,40 & 0,75 & 0,47 & 0,70 \\
\hline $\begin{array}{l}\text { Объемом финансирования с учетом } \\
\text { покупательной способности }\end{array}$ & 0,34 & 0,46 & 0,37 & 0,50 \\
\hline & \multicolumn{4}{|c|}{ Ожидаемая продолжительность жизни при рождении } \\
\hline $\begin{array}{l}\text { Объемом финансирования региональной ПГГ } \\
\text { на душу населения }\end{array}$ & $-0,36$ & $-0,52$ & $-0,23 *$ & $-0,33^{*}$ \\
\hline $\begin{array}{l}\text { Объемом финансирования с учетом } \\
\text { покупательной способности }\end{array}$ & $-0,35$ & $-0,48$ & $-0,22 *$ & $-0,30 *$ \\
\hline
\end{tabular}

* Включая регионы Центрального, Северо-Западного, Южного, Приволжского федеральных округов и Ставропольский край.

Примечание: Коррелящия значима на уровне 0,05, другие коэффициенты значимы на уровне 0,01.

Источник: расчет авторов 
Получается, что в регионах, где объемы финансирования выше, продолжительность жизни ниже, чем в регионах с более низким объемом финансирования.

Поиски других стран с близкой ситуацией не дали результатов. Мы сопоставили данные о среднем доходе на душу населения в штатах CША [U.S. Census Bureau 2016] с данными об ожидаемой продолжительности жизни населения штатов [U.S. County Profiles 2016]. Расчеты за 2010 г. дали коэффициенты ранговой корреляции Кендалла и Спирмена между ожидаемой продолжительностью жизни и средним доходом на душу населения, соответственно, равные 0,34 и 0,47 , значимые на уровне 0,01 .

Согласно расчетам Де Вогли и соавторов [De Vogli et al. 2005] для 20 регионов Италии в 2000 г., коэффициент корреляции Пирсона между доходом на душу населения и ожидаемой продолжительностью жизни при рождении был равен 0,54.

Рехидор и соавторы [Regidor et al. 2003] изучали связь между доходами домохозяйств и ожидаемой продолжительностью жизни по полу в 50 провинциях Испании в 1980 и 1990 гг. Авторы нашли корреляцию только для женщин. В 1990 г. коэффициент корреляции Пирсона был равен 0,57 (значим на уровне 0,05 ).

В обоих исследованиях показано, что экономическое неравенство снижает продолжительность жизни. В Италии коэффициент корреляции между коэффициентом Джини в 20 регионах и ожидаемой продолжительностью жизни составляет $-0,8$, а для женщин в 50 провинциях Испании $-0,7$.

Не исключено, что отрицательная корреляция по регионам России отражает обратную причинно-следственную связь. Больше средств на здравоохранение выделяется так, где выше смертность и хуже ситуация со здоровьем

Итак, мы установили, что ожидаемая продолжительность жизни в России существенно ниже уровня, который по модели Престона соответствует российскому душевому ВВП. Более того, в 2010 г. разница между модельной и реальной продолжительностью жизни составляла 8,7 года и была самой высокой среди стран, участвующих в расчете. Следующей страной в списке был Казахстан, с отклонением от модельного значения в 6,5 года. Рост продолжительности жизни в России при замедленном росте ВВП после 2010 г. уменьшил отклонение к 2015 г. до 7,2 года.

Такое отклонение свидетельствует, что задача охраны здоровья и продления жизни имеют в современной России не самый высокий приоритет. В ином случае нынешний экономический потенциал России был бы вполне достаточен для существенного улучшения ситуации. Представляется уместным еще раз напомнить высказывание одного из родоначальников концепции человеческого капитала и нобелевского лауреата Амартии Сена [Sen 1998] о том, что уровень смертности является отражением способности общества к трансформации имеющихся экономических ресурсов в наиболее важный продукт здоровье нации.

Объяснения сложившейся ситуации, ссылающиеся на особенности природноклиматических условий, чрезмерное потребление алкоголя или невозможность быстро преодолеть возникшее в предшествующие десятилетия отставание от других стран, хотя и 
имеют основания, но отвергаются сравнением с другими странами, имеющими сейчас или в прошлом похожие трудности. Сложные климатические условия, характерные для некоторых субъектов федерации, подчеркнем, чей вес в общей численности населения отнюдь не велик ${ }^{1}$, наблюдаются и в Канаде, и на Аляске, и в Норвегии, где продолжительность жизни существенно выше. Польша и Эстония, до них - Финляндия, а в девятнадцатом веке - Швеция сумели в основном преодолеть трудности, связанные с чрезмерным потреблением алкоголя. Опыт Чехии и уже упомянутых Эстонии и Польши, а также ГДР говорит о том, что последствия стагнации и роста смертности в 1970-е и 1980-е гг., можно преодолеть довольно быстро.

Другой вопрос, как могло случиться, что в России зависимость ожидаемой продолжительности жизни от экономического положения региона практически отсутствует?

На субнациональном уровне зависимость ожидаемой продолжительности жизни от ВВП, вероятно, слабее, чем на национальном, поскольку межрегиональные связи уменьшают неравенство в уровне смертности. Однако, полное отсутствие влияния кажется странным.

Наиболее правдоподобным нам представляется следующее объяснение. Как мы видели, в регионах, где выше душевой ВВП, выше уровень среднедушевого дохода и существенно выше неравенство населения по уровню дохода. Весьма высокие доходы у небольшой части населения повышают среднедушевой доход в регионе, но мало влияют на ожидаемую продолжительность жизни. Разрыв в доходах между малой группой и остальным населением ничем не ограничен. Но продолжительность жизни малой группы вряд ли может оказаться выше мировых рекордов. Подчеркнем, что это не более чем правдоподобное объяснение, которое очень трудно проверить.

Высокий ВВП большинства богатых регионов России основан на доходах добывающих отраслей экономики. Было показано [Edwards 2016], что в странах с высокой долей добывающей промышленности в экономике, уровень развития систем здравоохранения и образования существенно ниже, чем в странах с тем же ВВП, но с низкой долей добывающих отраслей. Как следствие, в этих странах заметно ниже и ожидаемая продолжительность жизни. Вероятно, на уровне регионов эта закономерность выражена слабее, но, как мы видим, существует.

Возможно, отрицательная корреляция между объемом финансирования региональной ПГГ и продолжительностью жизни объясняется так: в регионах с более неблагоприятной ситуацией объем финансирования региональной ПГГ выше, что кажется естественным, но недостаточно высок для кардинального улучшения ситуации. В подтверждение этого предположения скажем, что Москва в 2010 г. в списке регионов по объему финансирования ПГГ занимала всего восьмое место. Ее опережали не только

\footnotetext{
${ }^{1}$ Согласно итогам переписи населения 2010 г. более половины населения России проживает в регионах, занимающих 6\% ее территории, целиком расположенных в Европейской части страны. Еще 25\% живут в регионах, занимающих 8\% территории. В их число кроме регионов Европейской части входят территории, расположенные на юге Урала и Западной Сибири, то есть в зоне вполне комфортной с точки зрения климата.
} 
некоторые регионы Севера и Дальнего Востока, но и Новгородская область (67-е место по продолжительности жизни и 24-е место по душевому ВВП), Вологодская область (51-е и 29-е места) и Челябинская область (30-е и 28-е места). С другой стороны, мы не можем учесть в какой мере это «отставание» компенсируется тем, что определенная часть населения столицы пользуется услугами федеральных медицинских центров и ведомственных клиник.

Важно отметить, что московский уровень душевого ВВП, согласно модели Престона, соответствовал продолжительности жизни 80,8 года, что на 6,7 года выше фактической. Таким образом, в Москве быстрое продвижение в экономическом развитии привело к меньшему, чем ожидалось снижению преждевременной смертности. Причины смерти, определяющие отклонение от кривой Престона, для Москвы примерно такие же, как для России в целом. Из 57 участвующих в расчетах стран лишь в шести душевой ВВП был выше, чем в Москве, а ожидаемая продолжительность жизни была выше в 27 странах.

\section{ЛИТЕРАТУРА}

Андреев Е. М. (2012). О точности результатов российских переписей населения и степени доверия к разным источникам информации // Вопросы статистики. 11: 21-35.

Зубаревич Н. В. (2003). Социальное развитие регионов России: проблемы и тенденции переходного периода. УРСС. М.: 65-66.

Папанова Е. К., Школьников В. М., Андреев Е. М., Тимонин С. А. (2018). Высокая продолжительность жизни москвичей после 80 лет — реальность или статистический артефакт? // Успехи геронтологии. 30 (6): 826-835.

ПРООН (2002). Доклад о развитии человеческого потенциала в Российской Федерации 2001 / Под общей ред. С.Н. Бобылева. М.: ИнтерДиалект.

ПРООН (2013). Доклад о человеческом развитии в Российской Федерации 2013. Устойчивое развитие: вызовы Рио. М.: РА ИЛЬФ. URL: http://www.undp.ru/documents/NHDR-2013.pdf (дата обращения: 01.02.2017).

РосБРиС (2017). Российская база данных по рождаемости и смертности Центра демографических исследований Российской Экономической Школы. http://www.demogr.nes.ru/index.php/ru/demogr_indicat/data (дата обращения: 01.02.2012).

Росстат (2011). Регионы России. Социально-экономические показатели. 2011: Стат. сб. М.

Росстат (2014). Регионы России. Социально-экономические показатели. 2014: Стат. сб. М.

Andreev E. M., V. M. Shkolnikov, A. Z. Begun (2002). Algorithm for decomposition of differences between aggregate demographic measures and its application to life expectancies, healthy life expectancies, parity-progression ratios and total fertility rates // Demographic Research 7: 499-522.

De Vogli R., R. Mistry, R. Gnesotto, G. A. Cornia (2005). Has the relation between income inequality and life expectancy disappeared? Evidence from Italy and top industrialised countries // Journal of Epidemiology and Community Health, 59: 158-162.

Eberstadt N. (2010). Russia's peacetime demographic crisis: dimensions, causes, implications. Seattle, Washington: National Bureau of Asian Research.

Edwards R. B. (2016). Mining away the Preston curve // World Development. 78: 22-36. 
EHA DB (2017). European Health for All database. URL: http://www.euro.who.int/en/data-andevidence/databases/european-health-for-all-database-hfa-db (дата обращения: 01.02.2017).

Georgiadis G., J. Pineda, F. Rodríguez (2010). Has the Preston curve broken down? // Human Development Research Paper 2010/32. UNDP.

HMD (2017). Human Mortality Database. URL: http://www.mortality.org/ (дата обращения: 01.02.2017).

PAHO (2014). Pan American Health Organization. Data and statistics. Regional Core Health Data Initiative. Table Generator System. URL:

http://www1.paho.org/English/SHA/coredata/tabulator/newTabulator.htm (дата обращения: 01.02.2017).

Preston S. H. (1975). The Changing relation between mortality and level of economic development // Population Studies. 29:231-248.

Preston S. H (2007). The changing relation between mortality and level of economic development // International Journal of Epidemiology. 36 (3): 484-90.

Regidor E., M.E. Calle, P.Navarro, V. Dominguez (2003). Trends in the association between average income, poverty and income inequality and life expectancy in Spain // Social Science and Medicine. 56: 961-971.

Sen Amartya (1998). Mortality as an indicator of economic success and failure // Economic Journal. 108, 446: 1-25.

U.S. Census Bureau (2016). Selected economic characteristics 2010-2014. American Community Survey 1-Year Estimates. Retrieved 2016-02-12. (дата обращения: 01.02.2017).

U.S. County Profiles (2016). Institute for Health Metrics and Evaluation. URL: http://www.healthdata.org/us-health/data-download. (дата обращения: 01.02.2017).

WHO Mortality Database (2017). URL: http://www.who.int/whosis/mort/download/en/index.html (дата обращения: 01.02.2017)

World Development Indicators (2017). URL: http://data.worldbank.org/indicator/NY.GDP.MKTP.PP.CD (дата обращения: 01.02.2017).

WPP (2017). UN World Population Prospects 2017, Department of Economic and Social Affairs. URL: https://esa.un.org/unpd/wpp/DataQuery/ (дата обращения: 01.02.2017). 


\title{
THE RELATIONSHIP BETWEEN MORTALITY AND ECONOMIC DEVELOPMENT IN RUSSIA AND ITS REGIONS
}

\section{EVGENY ANDREEV, VLADIMIR SHKOLNIKOV}

\begin{abstract}
Life expectancy in rich countries is usually higher than in poor ones. We checked whether this is true for the regions of Russia.

The object of the study was data for 2010, the year of the last population census. As a measure of longevity we used life expectancy at birth, while as a measure of wellbeing we used per capita GDP in US dollars at purchasing power parity.
\end{abstract}

The analysis is based on a comparison of regional data with the Preston curve, which describes the relationship between per capita GDP and life expectancy at birth. The curve was also determined for 2010 based on data from 57 countries where population statistics are suitable for the calculation of life tables.

We found that life expectancy in Russia is substantially below the level that the Preston model predicts on the basis of Russia's per capita GDP. In 2010, the difference between the model and real life expectancy was 8.7 years, the highest among the 57 countries involved in the calculation.

The dependence of life expectancy on the economic situation in the regions is practically nonexistent. The illusion of interdependence exists because Moscow stands out among other regions with its high GDP and high life expectancy. However, life expectancy in 2010 in Moscow was significantly lower than the level predicted by the Preston model. In the authors' opinion, the lack of a connection is explained by the fact that in regions with high GDP, the level of economic inequality is also high. High incomes of a small part of the population can raise the average level of economic indicators in the region, but lower mortality in a small group has little effect on the life expectancy of the whole population.

Key words: life expectancy, gross domestic product, Preston's curve, regions of Russia, economic inequality, inequality in mortality.

Evgeny M. Andreev (evand2009@yandex.ru), NATIONAl RESEARCH University Higher School of Economics, RUSSIA.

Vladimir M. ShKolnikov (shkolnikov@demogr.mpg.de), MAX Planck Institute for DEMOgraPHIC ReSEARCH, GERMANY.

DATE RECEIVED: DECEMBER 2017.

\section{REFERENCES}

Andreev E. M (2012). O tochnosti rezul'tatov rossiyskikh perepisey naseleniya i stepeni doveriya $\mathrm{k}$ raznym istochnikam informatsii [On the accuracy of the results of Russian population censuses and the level of confidence in different sources of information] // Voprosy statistiki. 11: 21-35.

Andreev E. M., V. M. Shkolnikov, A. Z. Begun (2002). Algorithm for decomposition of differences between aggregate demographic measures and its application to life expectancies, healthy life expectancies, parity-progression ratios and total fertility rates // Demographic Research 7: 499-522.

De Vogli R., R. Mistry, R. Gnesotto, G. A. Cornia (2005). Has the relation between income inequality and life expectancy disappeared? Evidence from Italy and top industrialised countries // Journal of Epidemiology and Community Health, 59: 158-162. 
Eberstadt N. (2010). Russia's peacetime demographic crisis: dimensions, causes, implications. Seattle, Washington: National Bureau of Asian Research.

Edwards R. B. (2016). Mining away the Preston curve // World Development. 78: 22-36.

EHA DB (2017). European Health for All database. URL: http://www.euro.who.int/en/data-andevidence/databases/european-health-for-all-database-hfa-db (accessed: 01.02.2017).

Georgiadis G., J. Pineda, F. Rodríguez (2010). Has the Preston curve broken down? // Human Development Research Paper 2010/32. UNDP.

HMD (2017). Human Mortality Database. URL: http://www.mortality.org/ (accessed: 01.02.2017).

PAHO (2014). Pan American Health Organization. Data and statistics. Regional Core Health Data Initiative. Table Generator System. URL:

http://www1.paho.org/English/SHA/coredata/tabulator/newTabulator.htm (accessed: 01.02.2017).

Papanova E.K., V.M. Shkolnikov, E.M. Andreev, S.A. Timonin (2017). Vysokaia prodolzhitel'nost' zhizni moskvichei posle 80 let - real'nost' ili statisticheskii artefakt? [High life expectancy of Muscovites at 80+ - reality or statistical artifact?] // Uspekhi Gerontologii. 30 (6): 826-835.

Preston S. H. (1975). The Changing relation between mortality and level of economic development // Population Studies. 29:231-248.

Preston S. H (2007). The changing relation between mortality and level of economic development // International Journal of Epidemiology. 36 (3): 484-90.

PROON (2002). Doklad o razvitii chelovecheskogo potentsiala v Rossiyskoy Federatsii 2001 [Report on Human Development in the Russian Federation 2001] / S.N. Bobylev, ed.

PROON (2013). Doklad o chelovecheskom razvitii v Rossiyskoy Federatsii 2013. Ustoychivoye razvitiye: vyzovy Rio [Report on Human Development in the Russian Federation 2013. Sustainable Development: the Challenges of the Rio]. M.: RA IL'F. URL: http://www.undp.ru/documents/NHDR-2013.pdf (accessed: 01.02.2017).

Regidor E., M.E. Calle, P.Navarro, V. Dominguez (2003). Trends in the association between average income, poverty and income inequality and life expectancy in Spain // Social Science and Medicine. 56: 961-971.

RosBRiS (2017). The Russian fertility and mortality database of the Centre for Demographic Research of the New Economic School. URL: http://www.demogr.nes.ru/index.php/en/demogr_indicat/data (accessed: 01.02.2017).

Rosstat (2011). Regiony Rossii. Sotsial'no-ekonomicheskiye pokazateli. 2011: Stat. sb. [Regions of Russia. Socio-economic indicators. 2011: Statistical bulletins]. Moskva.

Rosstat (2014). Regiony Rossii. Sotsial'no-ekonomicheskiye pokazateli. 2014: Stat. sb. [Regions of Russia. Socio-economic indicators. 2014: Statistical bulletins]. Moskva.

Sen Amartya (1998). Mortality as an indicator of economic success and failure // Economic Journal. 108, 446: 1-25.

U.S. Census Bureau (2016). Selected economic characteristics 2010-2014. American Community Survey 1-Year Estimates. Retrieved 2016-02-12. (accessed: 01.02.2017).

U.S. County Profiles (2016). Institute for Health Metrics and Evaluation. URL: http://www.healthdata.org/us-health/data-download. (accessed: 01.02.2017). 
WHO Mortality Database (2017). URL:

http://www.who.int/whosis/mort/download/en/index.html (accessed: 01.02.2017).

World Development Indicators (2017). URL:

http://data.worldbank.org/indicator/NY.GDP.MKTP.PP.CD (accessed: 01.02.2017).

WPP (2017). UN World Population Prospects 2017, Department of Economic and Social Affairs. URL: https://esa.un.org/unpd/wpp/DataQuery/ (accessed: 01.02.2017).

Zubarevich N.V. (2003). Sotsial'noye razvitiye regionov Rossii: problemy i tendentsii perekhodnogo perioda [Social development of Russia's regions: problems and trends in the transition period]. URSS. M.: 65-66. 